\title{
Biomedia: Life in Smithereens
}

\author{
Benjamin Goh \\ London School of Economics and Political Science, United Kingdom
}

\begin{abstract}
This article suggests that media theory could lend some vocabularies with which to map the technical infrastructures of life. Focusing on the digital production of life, we read Marshall McLuhan's concept of media alongside 'Smithereens', the second episode of the fifth instalment of the Netflix digital television series Black Mirror.
\end{abstract}

Keywords: dispositif; media; life; digital; television; media theory; Black Mirror.

\section{Between Dispositif and Media}

In 1748, there arose an anonymous publication about a magic silver ring with a centre stone that, when pointed at female genitalia, elicits the speech of their past sexual experiences. ${ }^{1}$ Having received it as a gift from his genie, the Congo Sultan Mangogul would use the ring on 30 occasions, mostly as a means of diversion but finally to confirm the fidelity of his favourite mistress, before returning it.

This somewhat bawdy piece of fiction by Denis Diderot would later open 'The Deployment of Sexuality [Le dispositif de sexualité]', the fourth part of Michel Foucault's The History of Sexuality, Vol 1 (1980), as an allegory of the project at large. 'The aim of this series of studies? To transcribe into history the fable of Les Bijoux indiscrets'. ${ }^{2}$ As Foucault clarifies, the task is not so much to rehearse what has been said about sex in Western societies from around the sixteenth to nineteenth centuries as to reconstitute its historical conditions of possibility. 'It is this magical ring, this jewel which is so indiscreet when it comes to making others speak, but so ineloquent concerning one's own mechanism, that we need to render loquacious in its turn; it is what we have to talk about'. ${ }^{3}$ Hence, Foucault reconstructs the technical machinery that has produced sexuality in the historical period: 'a great surface network in which the stimulation of bodies, the intensification of pleasures, the incitement to discourse, the formation of special knowledges, the strengthening of controls and resistances, are linked to one another, in accordance with a few major strategies of knowledge and power'. ${ }^{4}$ The dispositif of sexuality involves a series of mutually reinforcing techniques, ranging from the bourgeois practices of penance and psychoanalysis to the broader population controls on procreation and perversion that penetrated the bodies of persons and produced the four sexual figures of the nineteenth century: 'the hysterical woman, the masturbating child, the Malthusian couple, and the perverse adult'. ${ }^{5}$ Foucault suggests sexual life to be not so much a natural given as a historico-technical product.

The concept of dispositif endures beyond the works of Foucault, having its longevity assured by a series of interventions in critical theory. ${ }^{6}$ Performatively, Gilles Deleuze remaps Foucault's historical analysis of concrete social apparatuses and their

\footnotetext{
${ }^{1}$ Diderot, Les Bijoux Indiscrets.

${ }^{2}$ Foucault, History of Sexuality, 77.

${ }^{3}$ Foucault, History of Sexuality, 79.

${ }^{4}$ Foucault, History of Sexuality, 105-106.

5 Foucault, History of Sexuality, 105.

${ }^{6}$ Other than the works of Agamben and Deleuze, see also Esposito, "Dispositif of the Person."
}

This work is licensed under a Creative Commons Attribution 4.0 International Licence. As an open access journal, articles are free to use with proper attribution. ISSN: 2652-4074 (Online) 
criss-crossing vectors of visibility, enunciation, force, subjectification, sedimentation and change as a sort of critical or processual cartography. 'Untangling these lines within a social apparatus [dispositif] is, in each case, like drawing up a map, doing cartography, surveying unknown landscapes, and this is what he [i.e., Foucault] calls "working on the ground.", ${ }^{7}$ Like Foucault, Deleuze recognises dispositif to be the historical a priori of human subjects: 'a line of subjectification is a process, a production of subjectivity in a social apparatus [dispositif]; it has to be made, inasmuch as the apparatus allows it to come into being or makes it possible'. ${ }^{8}$ In the historical diagram, persons are not so much the agents of change as its incidental effects.

Giorgio Agamben, too, affirms dispositif to be 'a decisive technical term in the strategy of Foucault's thought' ${ }^{9}$ Constellating it with Hegel's Positivität and Heidegger's Gestell, the Italian philosopher reads Foucault's dispositif as an appropriation of the Christian theological legacy of oikonomia: 'the administration of oikos (the home) and, more generally, management'. ${ }^{10}$ Agamben's innovation is to reformulate dispositif as the historical element that puts living beings at stake: 'I shall call an apparatus literally anything that has in some way the capacity to capture, orient, determine, intercept, model, control, or secure the gestures, behaviors, opinions, or discourses of living beings'. ${ }^{11}$ This bio-historicity comprises not only the juridico-political institutions in place but also the prevailing media technologies: 'Not only, therefore, prisons, madhouses, the panopticon, schools, confessions, factories, disciplines, juridical measures, and so forth (whose connection with power is in a certain sense evident), but also the pen, writing, literature, philosophy, agriculture, cigarettes, navigation, computers, cellular telephones and - why not - language itself, which is perhaps the most ancient of apparatuses — one in which thousands and thousands of years ago a primate inadvertently let himself be captured, probably without realizing the consequences that he was about to face'. ${ }^{12}$ Media do not simply communicate information, but might well imply far more complex processes of (de)subjectification.

This brief itinerary of dispositif indicates that media have come a long way from their place in the history of thought as passive objects destined to bear the will of persons. Not unlike Diderot's magic ring, media and things seem to exercise a peculiar agency that challenges traditional or legal accounts of the sovereign subject. Agamben's take on dispositif suggests that any study of the historical grids that produce human subjectivities has to take account of their constitutive media. But with which methodological concepts could we approach the mediality of these technical infrastructures of life? Is the thought of dispositif sufficient to articulate and clarify the relation of media to life? Are there other vocabularies that could advance the historical enquiry into the processes of subjectification, and perhaps reshape our understanding of dispositif?

This article suggests that media theory, and particularly that of Marshall McLuhan, could be useful to such ends. McLuhan conceives the medium as that which conditions individual psyches and social relations, the concept of which is arguably of much value to the study of the medial constitution of life, especially life in the global digital present. We read McLuhan alongside 'Smithereens' (2019), the second episode of the fifth instalment of the Netflix digital television series Black Mirror. A digital medium that not only thematises but mediates the radical reconfiguration of life by the ubiquitous use of digital technology today, even up to the point that it becomes, for some of its users at least, all but unliveable. This media-theoretical reading of 'Smithereens' is meant to demonstrate the utility of media theory to the inquiry into the digital (de)constitution of life, and further to suggest its value to the idiom of dispositif. It might be that any work interested in the politics surrounding the constitution of life would have to take seriously the place of media in the historical situation. If there is a figure that could encapsulate or adequately reflect the interests of this article, it might be that of 'biomedia': a theoretico-empirical merger of media and life, the relation between which could perhaps no longer be ignored in the field of biopolitics.

\section{Can the Medium Speak?}

'Three years ago I was driving home with her. We'd been visiting my mum. My mum was sick and we'd been visiting my mum and I was driving Tamsin back to our flat. She was asleep. She was tired and I'm just driving her home. And it was boring. I got bored. I got bored every ten seconds back then, I think, and I'm on this A road. It was very quiet, straight [PHONE VIBRATES] and my phone lights up and I check it. I just glanced at it, you know. There's this little notification thing saying someone liked a comment that I made about some photo of theirs. I just glanced at it, you know. That's all the time it took

\footnotetext{
${ }^{7}$ Deleuze, "What Is a Dispositif?," 159.

${ }^{8}$ Deleuze, "What Is a Dispositif?," 161.

${ }^{9}$ Agamben, What Is an Apparatus?, 1.

${ }^{10}$ Agamben, 8. See also Hegel, "Positivity of the Christian Religion"; Heidegger, "Question Concerning Technology."

${ }^{11}$ Agamben, What Is an Apparatus?, 14.

12 Agamben, What Is an Apparatus?, 14.
} 
[CRASH, GLASS SHATTERING] [METAL GROANS, TYRES SCREECH]. It took her two months to die. I was at her bedside. It was no use. The man in the other car died too'. ${ }^{13}$

Apparently, the coroner's report had lied. Or, at least, the forensic inquiry was incomplete. If the confession of the fiancé, Christopher Gillhaney, bears any weight, the fatal collision could not have been simply attributed to the drunkenness of the driver. Another intoxication was at play. 'I was the whole cliché, you know, the first thing I saw in the morning, last thing I saw at night' ${ }^{14}$ One possibly shared between the living and the dead. 'Tamsin was ... Tamsin was the same'. ${ }^{15}$ The irony being that something so reliant on screens had evaded the toxicologist's.

In the cacophony of '[GLASS SHATTERING]' there doubles the irruption of digital technology into everyday life. An interruption of pre-existing patterns of behaviour associated with older technologies such as writing and print. Chris and Tamsin were hooked on the social media application 'Smithereen', which was founded by a man called Billy Bauer. When Billy Bauer asks his employee Tipi to 'make a note' ${ }^{16}$ relating to the social media profile of the fiancé-turned-kidnapper, she performs the task with her smartphone and thumbs. Obsolescence would appear to have befallen the mechanical techniques of pen and paper.

'And it was boring. I got bored. I got bored every ten seconds back then, I think'. To speak of one's addiction in the past tense is to claim some sort of transcendence from it. Perhaps the collision also broke the spell of Chris's enthralment with the digital screen and the illusion that it had solved the problem of boredom. In its return to haunt Chris, there arises the suggestion that, with the advent of digital media, boredom was never truly satisfied, but simply deferred. Whereas the mirage of its satisfaction has exploded for Chris, it remains more or less undisturbed for other users. Hence, three years after the crash, while sitting in a café, Chris could be assailed by repetitions of the very visible, audible and tactile interruption that had facilitated it: '[PHONE VIBRATES] [PHONE VIBRATES] [PHONE BUZZING] [BREATHES SOFTLY] [PHONE KEYS CLICKING, BUZZING] [MUFFLED VOICES] [PHONE VIBRATES] [PHONE KEYS CLICKING] [MUFFLED VOICES, PHONES BUZZING] [AMBIENT NOISES INCREASES IN VOLUME]'. A palpable sensory overload that hastens Chris's breathing and expels him from the café. Smithereen and other social media continue to dominate their users.

Directed by James Hawes and written by Charlie Brooker, 'Smithereens' is the second episode of the fifth and latest instalment of the Netflix digital television series Black Mirror. The series comprises standalone episodes that critique digital technology and culture, and, thus, sits uneasily with the stream-based entertainment platform in which it is housed. The episode title harbours an ambivalence that permeates and splits the programme's content and, as we shall see later, its very medium. According to the Oxford English Dictionary, the phrases 'to knock, smash, blow, cut, etc., to (also into) smithereens' mean 'to knock, smash, blow up, etc., into tiny fragments'. ${ }^{17}$ For the social media application on which Chris and Tamsin were hooked to bear the name 'Smithereen' is to invoke the transitive verbal form 'to smithereen', which also means 'to smash or blow up into tiny fragments'. And as the scene of the fatal collision suggests, the object of the sentence meted out by social media might be the very life of their users. ${ }^{18}$

Before attending to some of the medial prescriptions of 'Smithereens', it is helpful to derive a sense of its plot. Chris Gillhaney, a 33-year-old rideshare driver, picks up passenger Jaden Tommins from the London office of Smithereen, whom he confirms to be working for the social media company. Instead of going to the airport as directed, Chris holds Jaden hostage at gunpoint in his car, which has stalled in the middle of a field after a police chase. Chris's demand is to speak with Billy Bauer. Despite discovering that Jaden is only a 22-year-old intern in his first week of work, with Jaden's help, Chris reaches Smithereen's chief operating officer Penelope Wu by phone and conveys his demand. Penelope hesitates to comply and stalls for time as she and the police strategise to defuse the situation. Meanwhile, news of the abduction disseminates via social media, facilitated by two teenage cyclists. Subsequently, against Penelope's advice, Billy Bauer calls Chris, who confesses his complicity in the collision that killed his fiancée, Tamsin. In turn, Billy Bauer admits that though it was not so envisioned initially, Smithereen was later designed to be increasingly addictive. He further accedes to Chris's request for a password to another social media account with 'Persona', whose founder Billy Bauer knows. This account belongs to a 20-year-old college student, Kristin, who recently committed suicide. Her mother believes that it contains the explanation for her death. Earlier, Chris had slept with the grieving mother after a social group meeting, and witnessed her obsession with accessing the account. Chris decides to let Jaden

\footnotetext{
${ }^{13}$ Hawes, "Smithereens."

${ }^{14}$ Hawes, "Smithereens."

${ }^{15}$ Hawes, "Smithereens."

${ }^{16}$ Hawes, "Smithereens."

${ }^{17}$ Oxford English Dictionary Online, Smithereens.

18 Vismann, "Cultural Techniques and Sovereignty," 83.
} 
go. But aware that Chris is likely to kill himself thereafter, Jaden tries to take the gun from him. Seeing that a struggle endangering the hostage has ensued, the police chief authorises the sniper to shoot Chris. The first shot misses. The pulling of the trigger for the second shot coincides with the mother pressing the enter key after having carefully inputted the password to Kristin's Persona account. In successive scenes, social media users are shown checking their phones in response to a notification, presumably a social media update on the outcome of the hostage situation. Immediately thereafter, their lives carry on as if undisturbed.

The summary might work in that it gives a defensible account of the probable cause(s) and consequence(s) of the piece's central action: the hostage situation. Driven by an inability to confess his guilt to anyone but Billy Bauer, Chris succeeds in doing so by holding the intern, Jaden, hostage, but possibly only to have himself killed. Except that in the priority that it grants to personal actors the summary already betrays the medium. Consider the sentence structure: for the most part occupying the position of the grammatical subject is a human being. The attribution of responsibility to personal actors is the traditional or legal perspective that the idioms of media theory and cultural techniques disavow. ${ }^{19}$ Rather, it might be that whatsoever action only arises pursuant to a historically specific encounter between the human and the non-human. ${ }^{20}$ It could be suggested that Black Mirror is a self-reflexive television series that, similarly, refuses the juridical image of sovereign subjecthood. Consider the opening title sequence: against a black background, a loader icon in the form of a neatly segmented metallic icon rapidly lights up in beat with a steady electronic whirring. On the brink of completion, the icon suddenly dissembles itself into its constitutive parts, dispersing, mutating and multiplying into triangles, circles, semicircles and assorted geometrical shapes, all the while accompanied by abrupt, irregular jolts and buzzes, as if having lost all sense of direction and control. A prolonged beep signals its arrival at a relatively stable formation consisting of the words 'BLACK MIRROR'. But as if conscious of the residual humanity in their very legibility, the letters begin to pulsate and shake. Tension builds as a humming crescendos. At its climax, a crack emerges, diagonally splitting the words, revealing a broken glass or screen from which the words are projected. Black Mirror exposes the very mediality of its interface and crosses out its legal title. In this self-reflexive gesture, the programme undoes itself. The episode 'Smithereens', in its allusion to the opening title sequence, could as well allegorise the Black Mirror series. The image of the sovereign subject and its self-fascination are doubly smithereened.

And yet, might this not have been intended by the creator of Black Mirror, Charlie Brooker? The paradox is that the opening title sequence and what resembles its auto-decomposition are engineered by human actors. The apparent 'mastery' over the medium therein displayed sits uneasily with the suggestion of its self-reflexive questioning. So, is it the programme's content or the medium speaking? The human or the non-human? Either or both? Neither? Assuming that all this has in some sense been anticipated by Brooker, the possibility of such a critical turning of the medium against itself is also necessarily prescribed by the digital apparatus. The critical effect cannot precede the medial condition that affords it. Which suggests that the paradox resists simple resolution.

\section{Outside Digital Culture}

'Black Mirror' fades to black. ${ }^{21}$ You hear waves breaking on the shore. Their calm, regular rhythm is soon joined by the rippling resonance of a chime. A masculine voice speaks: 'Now, once more return your attention to the breath'. Coinciding with a soft exhalation is the close-up of a left eye, shut, with a thick eyebrow. The waves continue to break. Another soft knock on the chime, followed by another soft exhalation. 'Notice how your breathing continues'. Now a close-up of the head unit of a car. The steering wheel is covering a quarter of a screen identifying the audio track: 'Guided Meditation (30 mins).mp3'. The artist and album are 'Unknown'. So too is the album art 'UNAVAILABLE', its thumbnail a grey square with a line struck diagonally across. Above the track details, the blue audio waveform expands and distorts itself in beat with the remaining syllables of the sentence: 'all by it-self', thereafter returning to its calm, regular undulation. The rear-view mirror shows both eyes this time: a man, whom we later know to be Chris. He continues to exhale softly, as the serene background sounds insist. There comes a split-second flashback of a car driving along an A-road in the first-person perspective. Chris flinches. 'Your mind may wander', the voice continues. He exhales softly again. 'Simply watch it go'. Another chime resounds, but this time audibly electronic. Chris's eyes open suddenly as he gasps. Erratically his gaze flickers, as if displaced or disoriented. The electronic chiming repeats. 'Calmly ...' Now a close-up of the rideshare 'Hitcher' application on a 4G smartphone, WIFI connected with a strong signal of three bars, 84 per cent battery left, the time is 14:22. Part of a map is shown. Like an aperture, the spotlight falls on the cartographic representation of 'Smithereen UK Office', greying out the rest of the map. A pop-up box above it reflects:

\footnotetext{
${ }^{19}$ Vismann, "Cultural Techniques and Sovereignty," 84.

${ }^{20}$ Latour, "Where Are the Missing Masses?," 225-258.

${ }^{21}$ Hawes, "Smithereens."
} 
'NEW FARE [line break] Skillane Street, London, EC4N [line break] Distance from you: 63ft [line break] User rating: $\star \star \star \star \star \star$ '. An icon of a person appears. '... and without judgement'. Quickly switching off the audio track, Chris returns his stern gaze to the application, pausing to read. 'Swipe to Accept', the application instructs visually. Accordingly, Chris's thumb brushes across the screen to the right. 'Confirm?' it asks. He repeats the gesture. 'Fare Accepted', it declares. The aperture disappears and the rest of the map regains colour and visibility.

A more traditional thematic analysis of this opening scene might underscore the clear parallel between Chris's desire to return to the peace in meditation and Billy Bauer's silent retreat. Penelope's initial justification to her colleagues for not complying with Chris's demand to speak with Billy Bauer is so as not to disrupt the latter's brief hiatus from digital culture. 'He's six days into a ten-day silent retreat. Just him alone, not speaking to anyone, total isolation. He's done tech detox weekends here and there, but ten days. And I'm very reluctant to step into that'. ${ }^{22}$ When Penelope finally gives in, the first scene we see of Billy Bauer is a bare-chested, unshaven, pony-tailed man sitting cross-legged in a high-ceilinged, glass-walled, minimally furnished house standing on a wooden structure. The house oversees an arid landscape with only dirt roads, sparse desert vegetation and rocks. The chyron locates the minimalist abode in the fictitious 'Furnace Valley, Utah'. With the bare, wide, naturalist setting comes a peace seemingly far removed from the technological disturbances of the urban café that repelled Chris. 'Oh, fuck!' snaps Billy Bauer as he hears from Tipi the news of the hostage situation. At the end of the episode, this time after an electronic notification of its outcome, Billy Bauer is seen taking off his glasses and returning to his 'tech detox', once more desirous of a break from digital culture. The final close-up is of Billy Bauer closing his right eye, a clear mirror image of Chris meditating in the opening scene. In this parallel search for a break from digital technology and culture, the message of 'Smithereens' appears to be that people should quite literally take their eyes off their phones and reclaim awareness and control of their bodies and lives more generally. 'You're just too good to be true / I can't take my eyes off you / You'd be like heaven to touch / I wanna hold you so much / At long last love has arrived / And I thank God I'm alive'. ${ }^{23}$ The message here seems to be for us to return to what precedes digital media: to the body and its natural rhythms. Our focus is perhaps to shift from the fascinating screen without to the gentle breathing within, the latter whose calm, regular alternation between exhalation and inhalation finds its geological cognate in the breaking and receding waves that opened the episode.

'In a culture like ours, long accustomed to splitting and dividing all things as a means of control, it is sometimes a bit of a shock to be reminded that, in operational and practical fact, the medium is the message'. ${ }^{24}$ The general tendency in Western society, McLuhan suggests, is instead to focus on what is presented by means of the medium: its ostensible 'content'. Consider the electric light as McLuhan did. ${ }^{25}$ Although a range of visually demanding activities require as their technical a priori the electric light, the medium is for the most part ignored. But, without its illumination, information simply could not pass between the human actors. "The electric light escapes attention as a communicative medium just because it has no "content." 26 Akin to the written records or files of Western law and culture, optical media such as the electric light "remain below the perception threshold of the law ${ }^{27}$ and its faithful subjects.

McLuhan's approach to the relation between media and culture could be read as comprised of two hypotheses, both of which are raised in the following sentence explaining what he understood by the 'message' of the medium. 'This is merely to say that the personal and social consequences of any medium - that is, of any extension of ourselves - result from the new scale that is introduced into our affairs by each extension of ourselves, or by any new technology'. ${ }^{28}$ The first proposition is that media extend the senses or functions of men (and women). Consider McLuhan and Quentin Fiore's illustration of this by means of the print medium: 'The wheel [next page] ... is an extension of the foot [two pages later] the book [next page] is an extension of the eye ... [next page] clothing, an extension of the skin ... [next page] electric circuitry [line break] an extension of the central nervous system [next page] men change' ${ }^{29}$ By separating what could otherwise be contained in a sentence into several pages imprinted with photographs of each of the medially extended senses (i.e., a foot, a wheel, thumbs on the sides of a book, an eye, a bare-chested woman with arms outstretched and multidirectional arrows extending from a circular centre), McLuhan

\footnotetext{
${ }^{22}$ Hawes, "Smithereens."

${ }^{23}$ A version of the love song, 'Can't Take My Eyes Off You,' originally by Frankie Valli and the Four Seasons, plays at the end of the episode.

${ }^{24}$ McLuhan, Understanding Media, 7.

${ }^{25}$ McLuhan, Understanding Media, 8-9.

${ }^{26}$ McLuhan, Understanding Media, 9.

${ }^{27}$ Vismann, Files, 11.

${ }^{28}$ McLuhan, Understanding Media, 7.

${ }^{29}$ McLuhan, Medium Is the Massage, 31-41.
} 
and Fiore literally defer the completion of the sentence and demonstrate the extensional function of media. 'All media are extensions of some human faculty - psychic or physical'. ${ }^{30}$

The second hypothesis builds on the first. The cultural effects deriving from the medial extensions of the human are parsed into 'personal and social consequences'. ${ }^{31}$ Schemata of perceptibility are fundamentally (re)configured by technology, which affect the sociability of persons. Consider here Lemur Gulliver's account of his encounter with the lady giants of Brobdingnag. ${ }^{32}$ Partly by virtue of his relative smallness, Gulliver was granted access to the naked bodies of the Maids of Honour who served the Queen. The tremendous amount of optical data that he could retrieve has famously been read to be analogous to that of microscopic vision. ${ }^{33}$ Optical instruments like the magnifying glass and scientific microscope produce magnified images up to tens, hundreds and possibly thousands the size of the specimen as it appears to the naked human eye. Gulliver directly referenced the magnifying glass, reflecting on some of the implications of his encounter with the Nurse's optically augmented 'monstrous breast' ${ }^{34}$ With his microscopic vision, the otherwise attractive Maids of Honour too were 'very far from being a tempting Sight' ${ }^{35}$ Filled with 'horror and disgust' ${ }^{36}$ at what he could see, Gulliver was physically compelled to stay away from them, thus, indicating a clear social effect of estrangement.

It has been suggested that the message of 'Smithereens' is for us to take a step back from digital culture and to be re-attuned to the natural rhythms of our bodies. If a return from culture to nature is urged, occupying the latter position would be the waves that open the picture. But by whom is the message communicated here? Recall the head unit of the car: above the words on the screen flow hypnotic electric blue waves, expanding and contracting, ostensibly an effect of audio waveform visualisation. The graphic reminds us that the waves breaking on the shore of Chris's ears, lulling the listener to a sort of blissful sleep, are digitally transmitted. The words further tell us that all the acoustic data Chris retrieves by means of his car's audio system, including the voice guiding him in the meditation, are encoded in the digital format of the mp3. Not to mention their communication to the viewers of 'Smithereens' along with the rest of its optical data, which digital content on Netflix are entirely accessed by means of digital screens and audio systems. How then might its digital recording and reproduction of sound and light affect the claim that 'Smithereens' is calling for some sort of prelapsarian return resembling a 'tech detox'?

On one reading, the digital mediation of the content not so much problematises the claim as qualifies it. The return to nature is not to be imagined as achieved independently of digital technology, but with its necessary assistance. Consider McLuhan's suggestion that media are 'the extensions of Man' ${ }^{37}$ with far-reaching personal and social consequences. If it is an extension of human faculties that technology achieves in the first instance, then surely might a digital medium like the mp3 be understood as a helpful extension that could facilitate the return. Perhaps an extension of the central nervous system: 'During the mechanical ages we had extended our bodies in space. Today, after more than a century of electric technology, we have extended our central nervous system itself in a global embrace, abolishing both space and time as far as our planet is concerned'. ${ }^{38}$ According to McLuhan, in so extending the central nervous system, electricity counteracts and reverses the detribalising effects of the letter and print. ${ }^{39}$ As defined by the Oxford English Dictionary, the central nervous system 'coordinates and integrates neural function, consisting of the brain and spinal cord (in vertebrates)'. ${ }^{40}$ It is not unlike the central processing unit of the computer, which performs the necessary data processing for its use. Electricity allows instantaneous communication channels to be formed between persons, by which data and experiences could be shared. Whereas the visual emphasis of print had facilitated the individuation of Western society, the infrastructural extension of electricity drives the integration or reconciliation of persons. The radio, for instance, allows for acoustic data such as the human voice to be projected to the remote listener in high definition and, thus, effectively bridges the distance between persons. With this form of electrical acoustic communication, the 'depth of experience' ${ }^{\prime 1}$ offered by the spoken word is not lost but effectively extended. 'That

\footnotetext{
${ }^{30}$ McLuhan, Understanding Media, 26.

${ }^{31}$ McLuhan, Understanding Media, 11.

${ }^{32}$ Swift, Gulliver's Travels.

${ }^{33}$ Nicolson, Microscope and English Imagination.

${ }^{34}$ Swift, Gulliver's Travels, 82-83.

${ }^{35}$ Swift, Gulliver's Travels, 108.

${ }^{36}$ Swift, Gulliver's Travels, 108.

${ }^{37}$ McLuhan, Understanding Media.

${ }^{38}$ McLuhan, Understanding Media, 3.

${ }^{39}$ McLuhan, Gutenberg Galaxy.

${ }^{40}$ Oxford English Dictionary Online, Central Nervous System.

${ }^{41}$ McLuhan, Gutenberg Galaxy, 92.
} 
which had been the first great extension of our central nervous system - the mass media of the spoken word - was soon wedded to the second great extension of the central nervous system-electric technology'. ${ }^{42}$

Brought to bear on 'Smithereens', McLuhan's observations about electric media and the radio might suggest digital media such as the mp3 track to be extensions of the nervous system that bring people closer together. By means of the car audio system, the distance separating the meditation guide and Chris is effectively bridged. Conveyed to his ears are the calm, regular waves of the sea, previously heard by another pair of ears belonging to another human being of a different time. With the abolition of space and time signalled by the digital medium, human experiences could be shared and a return to nature in its plenitude becomes a real possibility. Not so much an obstruction or a diversion, digital media here seem to resemble a handy tool for the restoration of the integrity of persons. McLuhan's brief, theologically inflected thought on the computer's communicative capabilities could as well apply here. 'Today computers hold out the promise of a means of instant translation of any code or language into any other code or language. The computer, in short, promises by technology a Pentecostal condition of universal understanding and unity'. ${ }^{43}$

'In contrast to such an arch-catholic media cult, which simply confuses the Holy Spirit and Turing's machine, it is hopefully sufficient to point out that the development of all previous technical media, in the field of computers as well as optical technology, was for purposes directly opposed to cosmic harmony - namely, military purposes' ${ }^{44}$ The mutual entanglement of military history and technological history leads Friedrich Kittler to question McLuhan's reconciliatory and universalist vision of a global culture modelled on the computer. If harboured in the computer is an acculturative bias or set of cultural techniques oriented towards death and division, then the Pentecostal ideal cannot be uncritically endorsed.

'Electrics does not equal electronics' ${ }^{45}$ Kittler suggests that even though digital technology might draw on electrical power, its media in some sense differ from the electric media on which McLuhan had focused. He recalls a time when acoustic data was not digitally encoded. Prior to Albert Einstein's phonograph, Europe had only two means of arresting the time flow of acoustic data: 'texts and scores'. ${ }^{46}$ Western music is based on the diatonics of the seven notes from A to G. Speech, in turn, is recorded in literature by means of the system of 26 letters. Similarly, as musical notation operates by way of symbolic representation, it is a subsystem of the written word. In the monopoly of writing, 'all data flows ... had to pass through the bottleneck of the signifier' ${ }^{47}$ It was only with Einstein's public presentation of the prototype of the phonograph in 1877 that the possibility of storing physical effects of sound as soundwaves was raised. With the later arrival of Emile Berliner's gramophone, acoustic data could not only be recorded but also reproduced. As the storage of acoustic data then depended on the etching of acoustic vibrations from an original source onto a metallic disc, it was regarded as a form of analogue technology. Its optionality only came to be realised with the arrival of the Turing machine and the return to the Fourier transform.

Digital signal processing operates by way of an explicitly numerical method to achieve results that are comparable to, if not in excess of, analogue recording. With the Fourier transform, the computer could convert sound events into periodicities with numerical values, manipulate these values in whichever ways and then reproduce them as sound events. ${ }^{48}$ Alterations could be made to these values - to adjust their pitch, volume and tempo, for instance, or to reverse their temporal sequence-before they are recomposed and projected to enhanced effect. But where the gramophone is surpassed by the computer lies in the latter's capacity to simulate sound events by means of numerical calculations, that is, to produce them even if there had been no source with which to begin. Whereas analogue media for the most part operate within the limited frequency range of human senses, digital or technical media could access higher frequencies and, thus, produce sensory events that are not traceable to actual occurrences. 'Technical media ... are defined by nothing less than their strategy of subverting low-frequency ranges by being able to simulate them' ${ }^{49}$ Digital media are not only able to reproduce acoustic data that has been recorded but could, in fact, produce it from numbers. As Geoffrey Winthrop-Young notes: 'you can start with numbers and create lifelike sound events that never occurred in real life. Your eyes and ears won't be able to tell the differences because the media involved access frequencies and operate at speeds beyond all human thresholds'. ${ }^{50}$

\footnotetext{
42 McLuhan, Gutenberg Galaxy, 293.

${ }^{43}$ McLuhan, Understanding Media, 80.

${ }^{44}$ Kittler, Optical Media, 30.

${ }^{45}$ Kittler, Gramophone, Film, Typewriter, 2.

${ }^{46}$ Kittler, Gramophone, Film, Typewriter, 4.

${ }^{47}$ Kittler, Gramophone, Film, Typewriter, 4.

${ }^{48}$ Kittler, "Real Time Analysis, Time Axis Manipulation," 12.

${ }^{49}$ Kittler, "Real Time Analysis, Time Axis Manipulation," 9-10.

${ }^{50}$ See Winthrop-Young's introduction to Kittler, "Real Time Analysis, Time Axis Manipulation," 3.
} 
Returning to 'Smithereens', we could now note an ambiguity of provenance that surrounds the waves breaking on the shores of Chris's ears (and ours). Are these so-called natural waves that have been recorded and encoded in mp3 format before being transmitted via the car audio system and the sound systems of our digital devices? Or are they electronically synthesised waves and, thus, of digital origins? 'Unknown Artist', 'Unknown Album', 'Album Art Unavailable' - these suggestions that the audio track might have been downloaded illegally underscore its uncertain origins. Flowing as it were pointlessly and timelessly in the portable (and, thus, also placeless) screen, the hypnotic blue waves threaten to engulf the possibility of a return to nature. The masculine voice is the meditation 'guide' that is supposed to show the way 'outside' the digital monopoly. But if even the guide is digital through and through, then there might no longer be an outside digital culture.

\section{Death and Boredom in the Digital Monopoly}

'We can perhaps assume that the use of a medium of communication over a long period will to some extent determine the character of knowledge to be communicated and suggest that its pervasive influence will eventually create a civilization in which life and flexibility will become exceedingly difficult to maintain and that the advantages of a new medium will become such as to lead to the emergence of a new civilization'. ${ }^{51}$ In 1952, Harold A. Innis offered this set of three hypotheses pertaining to the relation of communicative media to life. They arose out of his extensive study of ancient and modern civilisations and their dominant modes of communication prior to the ascendency of digital technology. ${ }^{52}$ The middle suggestion that the prolonged and pervasive use of a communicative medium renders life increasingly unliveable strongly resonates with the plot of 'Smithereens'. With the corpses of Kristin, Tamsin and Chris piled atop the digital screen or, more accurately, dispersed across space and time by means of the mass-produced, portable digital devices of their former users, 'Smithereens' offers itself as an allegory of the difficulty of living with digital media. But how exactly is life rendered unliveable by the digital monopoly? How could media theory help us specify the relation?

'The effect of electric technology had at first been anxiety. Now it appears to create boredom' ${ }^{53}$ For McLuhan, the former effect of anxiety derives from the shock of the electric abolition of time and space, which departs from the older fragmentary patterns of the pre-electric age. It is the overwhelming ethical compulsion effected by the electrical contraction that generates anxiety. 'This is the Age of Anxiety for the reason of the electric implosion that compels commitment and participation, quite regardless of any "point of view." "54 In the electric age, print's perspective of the detached individual who is able to defer and dispense judgement from a distance is recognised to be insufficient to meet the demands of this new-found responsibility. 'It is no longer possible to adopt the aloof and dissociated role of the literate Westerner'. ${ }^{55}$

It is more difficult to explain the latter effect of boredom. Given the heightened sense of ethical responsibility in the electric age, it might seem a little odd for the mood of boredom to emerge. Would not the intensity of the compulsion and the urgency to act leave us not a second nor any room for the sort of desire for satisfaction implied in boredom? Why might this be the longterm effect of electric media and possibly digital technology? McLuhan does not offer a direct explanation for it, but perhaps we could suggest one by way of an alternative reading of the climax of 'Smithereens' that brings together the insights of McLuhan and others. Not unlike the film medium, ${ }^{56}$ the smartphone is able to transmit large amounts of data and excite the senses of its user. Except that in the instantaneity of its data flows, the latter surpasses the former by permitting social interactions. Thus, the smartphone is not only able to captivate the user, but can do so for extended periods. Portable, convenient and possessive of superior data functions, the smartphone offers an efficient relief to the boredom of everyday life. But a prolonged exposure to this highly stimulating medium could make exceedingly apparent the contrast between the highdefinition experience it offers and the unenhanced perception of the everyday; between the data capacities of technological extensions and those of our bodies. The so-called normal experience of living with our bodies might increasingly be regarded as inadequate or even deficient in comparison to the digitally mediated alternatives. Boredom is incessantly generated with each successive use of digital media and integrates into our so-called normal modes of being 'outside' the screen. Daily life dulls into an unbearable wait for the ecstatic time of the digital screen.

Let us recall Franz Kafka's parable of the man before the law. The man from the country had hoped to gain access to the law, but his journey by foot was interrupted by the forbidding words of the doorkeeper. 'It is possible', announced the doorkeeper,

\footnotetext{
${ }^{51}$ Innis, Bias of Communication, 34.

${ }^{52}$ Innis, Empire and Communications.

${ }^{53}$ McLuhan, Understanding Media, 29.

${ }^{54}$ McLuhan, Understanding Media, 5.

${ }^{55}$ McLuhan, Understanding Media, 5.

${ }^{56}$ McLuhan, Understanding Media, 314.
} 
'but not now'. ${ }^{57}$ Later he added, 'If you are so tempted, just try to enter in spite of my prohibition. But take note: I am powerful. And I am only the lowest doorkeeper. But from room to room stand doorkeepers each more powerful than the last. The mere aspect of the third is more than even I can endure'. ${ }^{58}$ The speech sank into the depths of the man's soul, shaking him from within. Having been stopped in his tracks by the spoken word, the man would have his stay prolonged by the doorkeeper's stool. Despite coming from the country, the man appeared to have been well acquainted with the cultural techniques of sitting and waiting. Perhaps for a long time in the country, and from a young age, he had used the stool and/or other sitting technologies to bear an otherwise unbearable wait. As if subjected to some sort of Pavlovian conditioning, the technological stimulus of the stool had long been associated with the biological stimuli relating to authority, fatigue and/or hesitation and become a trigger for the desire to comply, rest and wait. Prompted by the stool to sit, he obediently complied, secure in the medium's threelegged stability. With that, his feet ceased to move and forever assumed a position of passivity.

Apparently, Chris was destined to suffer a fate similar to that of the man from the country. They each had a goal or task, Chris's being to drive his fiancée home to safety. Whereas the man from the country had been stopped by the spoken word, Chris was confronted with its stark absence - the deafening silence of a lonely drive with an unconscious companion. How he longed to have the boredom relieved by any sort of sensory stimulus. '[PHONE VIBRATES] and my phone lights up'. With the acoustic and optical stimuli and their familiar promise of relief, Chris's boredom flared up and accordingly drove him to reach for the device and its possibility of instantaneous communications. Again, some cultural techniques were prescribed by the medium, this time those of pressing, swiping, scrolling through the social media application Smithereen, which necessarily diverted him from the original route. Obediently, his gaze shifted from the dimly lit road to the fully illuminated digital medium, which would seal his fate. Shortly before his death, the man from the country saw in the dark a radiance which [broke] out imperishably from the door to law'. ${ }^{59}$ Possibly a sign pointing to the law, if not the law itself. In its luminescence, the object of desire anachronistically recalls the shiny, glowing screen of Chris's smartphone, which likewise promised to solve the problem of existence. The light to put an end to the endless journey, myriad tours and unbearable wait in the dark; the truth to set him free from the boredom, restlessness and uncertainty of not knowing.

Except that the prospect of gratification might be superior to or more appealing than the actual experience. The knowledge disseminated by digital technology is a curious blend of the sacred and the profane. On the one hand, there are the so-called private, intimate correspondence between users safeguarded by the social media gods; on the other, there are the publicly circulated messages and photographs relating to the quotidian lives of users, ranging from third-party observations and judgements to the photograph of a pet dog. The latter category, which lacks the profundity and mystique of religious knowledge expressed by the colossal Egyptian pyramids, would appear to form the bulk of Chris's fascination, and perhaps that of most digital media users. ${ }^{60}$ The contents of social media could yield a quasi-religious following, but the contents themselves seem banal and pedestrian, suggesting they only offer minimal doses of gratification. Might it not be that the communications are at once meaningful and capable of momentarily seizing the attention of the user, and yet insufficient to provide a depth of meaning that could carry over into and sustain the so-called unmediated existence of the user? A social engagement that barely scratches the surface of existence, perhaps just enough to make the technologically unaided existence seem duller and, thus, prompt the user to return to the medium in spite of its disappointment. The bare satisfaction of curiosity that only keeps the desire for satisfaction running. The data capabilities of the smartphone afford the dissemination of large amounts of data, except that such data is for the most part of this limited sort, offering a kind of immediate relief to boredom, and yet inadequate to make living more bearable for extended periods. The tragicomedy of Chris's situation is that a momentary break in focus could yield lasting consequences: 'I just glanced at it, you know [CRASH, GLASS SHATTERING] [METAL GROANS, TYRES SCREECH]. That's all the time it took. It took her two months to die'. Chris's fate suggests that the advent of digital media does not solve the problem of boredom, but exacerbates it and ensures its longevity. Not unlike the law of Kafka's parable, the arrival of the solution — an eternal ecstasy or equilibrium — is interminably deferred.

\section{Futures of Biomedia}

But even if it is produced by the global digital infrastructure, must boredom be repugnant to our so-called freedoms? Then working in the idiom of dispositif, Agamben recalled Heidegger's suggestion of boredom to be one of two effects of the primordial separation of living beings from their environment. 'The break or interruption of this relationship produces in living beings both boredom - that is, the capacity to suspend this immediate relationship with their disinhibitors - and the Open,

\footnotetext{
${ }^{57}$ Kafka, Trial, 166.

${ }^{58}$ Kafka, Trial, 166.

${ }^{59}$ Kafka, Trial, 167.

${ }^{60}$ Innis, Bias of Communication, 93.
} 
which is the possibility of knowing being as such, by constructing a world'. ${ }^{61}$ Apparatuses like media are perhaps fabricated to dissipate the boredom of alienation, except that they might not always succeed and, indeed, often could involve the capture of living beings. 'At the root of each apparatus lies an all-too-human desire for happiness. The capture and subjectification of this desire in a separate sphere constitutes the specific power of the apparatus' ${ }^{62}$ A double tragedy that, as suggested by our analysis of 'Smithereens', seems to have acquired an aggravated inflection in the global digital monopoly. Later in the piece, Agamben would suggest that the process of subjectification activated by the cellular telephone fails to fulfil itself. 'He who lets himself be captured by the "cellular telephone" apparatus — whatever the intensity of the desire that has driven him — cannot acquire a new subjectivity, but only a number through which he can, eventually, be controlled'. ${ }^{63}$ We might add, now that the smartphone has proved to be capable of at least prolonging the capture with its dazzling screen, the process of subjectification has perhaps been enhanced to the detriment of its user. But does boredom not lend itself to be re-read and appropriated as a critical possibility? Could it not indicate the failure of digital subjectification and raise the possibility of counter-dispositifs, such as those generated by Deleuze and Agamben? ${ }^{64}$ Might 'Smithereens' and the Black Mirror series not be attempts to interrupt the fascination of the digital screen?

We began with the suggestion that life derives from the historical grid called dispositif, and then sought to show that media theory provides some conceptual tools with which to map the technical machinery. But which assumptions about the world are carried over by the transposed concept of media? In 1977, when Foucault defined dispositif as a 'thoroughly heterogeneous ensemble of ... elements, whether discursive or non-discursive', ${ }^{65}$ he seemed to assume some kind of equality between knowledge and its associated techniques. But as suggested in the preceding return to McLuhan, media theory makes no such assumption. For McLuhan, the key object of study is the medium that conditions the content. The priority of the technical over the message to be delivered is an assumption that recurs in many important works of media theory. It is implied in Kittler's displacement of Foucault's 'historical a priori' with the 'technical a priori', it is integral to Innis's suggestion that knowledge is shaped by the properties of the media that communicate it and it could be traced back to Claude Shannon's study of communications as an engineering rather than semantic problem. ${ }^{66}$ The entry of media theory into biopolitics might be violent, for it seems to introduce this technical priority. If we are to maintain a critical relation to this implicit precedence, then it is necessary to keep this assumption open to continual interrogation.

Indicating in its name the theoretico-empirical merger of life and media, the title figure 'biomedia' foregrounds the importance of attending to the transactions between the two metonyms for content and medium. Though there is perhaps no life without media, so too might there be no media without life. Could it be that media do not so much 'determine our situation' ${ }^{67}$ as condition it, just as media themselves are shaped by our situation? And might it not be that some relative autonomy of the human or the political insists in spite or because of the technical conditions of possibility? Such questions remain open.

\section{Acknowledgements}

It was a privilege to have presented a version of this article at the Law, Literature and the Humanities Association of Australasia 2019 Conference as a bursary recipient. I am grateful to Alain Pottage, Stephen Humphreys, Kieran Tranter, the three anonymous reviewers and others who made this possible.

\footnotetext{
${ }^{61}$ Agamben, What Is an Apparatus?, 16-17.

${ }^{62}$ Agamben, What Is an Apparatus?, 17.

${ }^{63}$ Agamben, What Is an Apparatus?, 21.

${ }^{64}$ As suggested by one of the reviewers, Jacques Derrida's deconstructive practice, too, could be regarded as a series of ethico-political performances that respond to our irreciprocal relation to justice. See, for example, Derrida, "Force of Law."

${ }^{65}$ Foucault, "Confession of the Flesh," 194-95.

${ }^{66}$ Kittler, Discourse Networks 1800/1900; Innis, Bias of Communication; Innis, Empire and Communications; Shannon, Mathematical Theory of Communication.

${ }^{67}$ Kittler, Gramophone, Film, Typewriter, xxxix.
} 


\section{Bibliography}

Agamben, Giorgio. What Is an Apparatus? And Other Essays. Translated by David Kishik and Stefan Pedatella. Stanford, CA: Stanford University Press, 2009.

Deleuze, Gilles. "What Is a Dispositif?" In Michel Foucault, Philosopher: Essays Translated from the French and German, translated by Timothy J. Armstrong, 159-168. New York: Routledge, 1992.

Derrida, Jacques. "Force of Law: The 'Mystical Foundation of Authority." " In Deconstruction and the Possibility of Justice, edited by Drucilla Cornell, Michel Rosenfeld, and David Gray Carlson, 3-67. Routledge, 1992.

Diderot, Denis. Les Bijoux Indiscrets, or, The Indiscreet Toys. Reprinted for Pierrot Ragout, 1749.

Esposito, Roberto. "The Dispositif of the Person." Law, Culture and the Humanities 8, no 1 (2012): 17-30. https://doi.org/10.1177\%2F1743872111403104

Foucault, Michel. "The Confession of the Flesh.” In Power/Knowledge: Selected Interviews \& Other Writings 1972-1977, edited by Colin Gordon, 194-228. New York: Pantheon Books, 1980.

- The History of Sexuality: Volume 1: An Introduction. Translated by Robert Hurley. New York: Pantheon Books, 1978.

Hawes, James, dir. Black Mirror. Season 5, episode 2, “Smithereens.” Netflix, Aired 5 June 2019.

Hegel, G. W. F. "The Positivity of the Christian Religion.” In Early Theological Writings, translated by T. M. Knox, 67-144. Philadelphia: The University of Pennsylvania Press, 1996.

Heidegger, Martin. “The Question Concerning Technology.” In Basic Writings, edited by David Farrell Krell, 2nd ed., 307343. New York: Harper \& Row, 1977.

Innis, Harold A. Empire and Communications. United States of America: Rowman \& Littlefield Publications, Inc., 2007. . The Bias of Communication. 2nd ed. Toronto: University of Toronto Press, 2008.

Kafka, Franz. The Trial. Penguin Random House, 1999.

Kittler, Friedrich. Discourse Networks 1800/1900. Translated by Michael Metteer and Chris Cullens. Stanford, CA: Stanford University Press, 1990.

- Gramophone, Film, Typewriter. Translated by Geoffrey Winthrop-Young and Michael Wutz. Stanford, CA: Stanford University Press, 1999.

_. Optical Media: Berlin Lectures 1999. Translated by Anthony Enns. Cambridge: Polity, 2010.

" "Real Time Analysis, Time Axis Manipulation." Cultural Politics 13, no 1 (2017): 1-18. https://doi.org/10.1215/17432197-3755144

Latour, Bruno. "Where Are the Missing Masses? The Sociology of a Few Mundane Artifacts." In Shaping Technology/Building Society: Studies in Sociotechnical Change, 225-58. Cambridge, MA: The MIT Press, 1992.

McLuhan, Marshall. The Gutenberg Galaxy. Toronto: University of Toronto Press, 2017.

- Understanding Media: The Extensions of Man. Cambridge, MA: The MIT Press, 1994.

McLuhan, Marshall and Quentin Fiore. The Medium Is the Massage: An Inventory of Effects. Berkeley, CA: Gingko Press, 2011.

Nicolson, Marjorie Hope. The Microscope and English Imagination. Northampton, MA: Smith College, 1935.

Shannon, Claude E. and Warren Weaver. The Mathematical Theory of Communication. Urbana: University of Illinois Press, 1998.

Swift, Jonathan. Gulliver's Travels. Oxford World's Classics. Oxford: Oxford University Press, 2005.

Vismann, Cornelia. Files: Law and Media Technology. Translated by Geoffrey Winthrop-Young. Stanford, CA: Stanford University Press, 2008.

. "Cultural Techniques and Sovereignty." Theory, Culture \& Society 30, no 6 (2013): 83-93.

https://doi.org/10.1177\%2F0263276413496851 